\title{
Governance Construction for Cooperation between Korea and ASEAN Supernational Security Issues
}

\author{
Kim Han Su \\ Mokwon University (Public Policy Department), Daejeon, South Korea \\ Email: theory80@naver.com
}

How to cite this paper: Su, K.H. (2019) Governance Construction for Cooperation between Korea and ASEAN Supernational Security Issues. Open Access Library Journal, 6: e5510.

https://doi.org/10.4236/oalib.1105510

Received: May 29, 2019

Accepted: June 18, 2019

Published: June 21, 2019

Copyright (C) 2019 by author(s) and Open Access Library Inc.

This work is licensed under the Creative Commons Attribution International License (CC BY 4.0)

http://creativecommons.org/licenses/by/4.0/

\begin{abstract}
Today, ASEAN is required to play a role strategically and economically as a key strategic point in East Asia. As the strategic and diplomatic importance of ASEAN cooperation expands, South Korea's ASEAN policy is, in fact, only the initial stage of exploring the cohesion points of regional security cooperation and economic cooperation. Currently, Korea needs to quickly establish policies to secure national interest and information in a rapidly changing international situation by clearly grasping ASEAN's international status. ASEAN is located in South Korea, it has the role of a supplement to relieve tension on the Korean peninsula, the role of an accelerator for jumping to a middle-sized country in East Asia, and an economically rich resource, labor force, in terms of diplomacy and security and as a main target of the defense industry, it is judged that it offers new opportunities for export sales channels. The way to cope with the current situation insists that it is most effective to use the "army", which has systems, resources and means constantly built in each country. In ASEAN, where East Asia's strategic importance and unlimited economic development potential are inherent, it is necessary to establish a mutually beneficial relationship that is in line with the strategic direction of the Korean government.
\end{abstract}

\section{Subject Areas}

International Relations

\section{Keywords}

ASEAN, Transnational Security Issue Neural Activations, International Cooperation 


\section{Introduction}

Today, ASEAN is required to play a role strategically and economically as a key strategic point in East Asia. The major powers such as the United States, China, and Japan will try to expand their own influence in the region. This is because the strategic value of Southeast Asia has become even greater in the process of forming the confrontation between the United States and China, due to the large flow of changes in the security situation in the world in which the competition between large powers has accelerated in 2010 [1].

However, while the strategic and international importance of the Southeast Asian region and ASEAN cooperation by major powers are expanding, South Korea's ASEAN policy is in the early stages of exploring the cohesion points of regional security cooperation and economic cooperation. The fact is that it is just passing. Southeast Asia, in most emerging industrial countries, has formed close ties with surrounding powers in response to the increasing interdependence of the global economy since the end of the 1990s and changes in the de-chilling security environment. In the case of South Korea, after the Moon-Jein administration, ASEAN has drawn a diplomatic plan for diplomatic security and economic expansion, and has spurred the establishment of strategic partnerships within the multilateral framework. The problem is that, until now, Korea's efforts in ASEAN diplomatic cooperation have been concentrated on humanities sociology and investment economic research in the field of vision presentation and regional research for future cooperation concept. The research on practical alternatives for the multilateral cooperation concept between Korea and ASEAN from the international political and security perspectives is absolutely lacking, and the research considered by some international political scientists has remained at the limit of the accompanying research of the supremacy competition between the United States and China.

This study aims to reaffirm the role and importance of ASEAN's national interests in South Korea and East Asia security cooperation, and to present the direction of future-oriented security cooperation. In addition, based on the "Asean way" of Southeast Asia, we will try to contribute to the necessity of establishing governance of transnational security issues and to establish the direction of Korea's defense foreign policy.

\section{ASEAN's Transnational Security Issue and the Meaning of Regional Cooperation Research}

The issue of global security after the end of the Cold War era is from the traditional military part of the "state-centred" concept for domestic security, to today's new non-traditional security such as natural disasters, energy and food issues. It extends to the issue of security, and discourses are made up of various issues [2]. A transnational issue that requires a regional partner level response beyond the framework of a single country in ASEAN was raised from the 1950s, but its urgency was not clearly recognized. However, the action rules and coop- 
eration measures among regional states to seek solutions to supranational issues triggered by "ASEAN Vision 2020" presented at the Second Informal Informal Meeting in 1997 The formation of (agreed rules of beharior and cooperative measures) was emphasized in earnest [3].

Among the transnational security issues that have recently emerged in ASEAN, terrorism, poverty, fog, human trafficking, infectious diseases, water resource development, migrant labor, etc. are representative [3]. These supranational security issues are real issues that the solution must immediately take as a source to seek out new regional cooperation schemes in ASEAN. Since the 1997 East Asian Currency Crisis, ASEAN has been required to work closely in various fields, ranging from changes in politics, economy and social systems in the region. $\mathrm{n}$ particular, transnational issues that cannot be solved at the single country level will be directly influenced to the understanding and involvement station beyond the scope of the region in the region. Until now, the limit of ASEAN's transnational security issue (unconventional security) has been, first of all, the majority of research focused on the level of one country, and secondly, the seriousness of unconventional security issues. While emphasizing gender but still focusing on traditional security and not considering various topics, Thirdly, the strategic role of the discussed regional cooperation body is a huge discussion, The point is that it is specific with emphasis on huge strategies, and remains at an abstract level that lacks practical aspects [3]. Recently, Korea has been making efforts to build a close and deep cooperation system for the construction of regional communities such as the "East Asia Railway Community" concept centering on the Korean Peninsula, on the premise of North-South peacebuilding. Not only in Korea, but also in the international community, ASEAN's transnational issue is to secure leadership in East Asia regional cooperation negotiations from the relatively free non-traditional security field, among other things, in the "Asean way". Competition will be intensified. Therefore, Korea, one of the countries that want to have regional leadership in East Asia, will also need to be concerned with ASEAN in order to solve these problems.

In this research, overcoming the level of stopping discourse in raising the need for conventional community response for transnational security issues such as disasters, terrorism, fog, poverty, infectious diseases, etc. for which there is a limit in dealing with the dimension of one country. Try to present a practical policy proposal.

\section{Evaluation and Development of Cooperation between South Korea and ASEAN over Transnational Security Issues}

South Korea and ASEAN have developed cooperative relations in various fields such as politics, security, economy, society and culture since establishing the conversation relationship in 1991 [1]. South Korea's ASEAN value in Chapter 2 important economic partners and resources trade and investment, we control 
the economic value as a labor department, the peace regime of the Korean Peninsula, the region to control the situation in East Asia We discussed the role of international relations, such as the role of cooperative partners. When South Korea's R-ASEAN policy became full-fledged, in the role of a partner, the Kim Dae Jung government played a central role in Korea's economic cooperation until the overcoming of the IMF economic crisis of 1997.

Until now, Korea's ASEAN policy has been discussed from various aspects depending on the government's national vision of the administration, its foreign political goals, and the security environment, and sometimes there has been congestion. Especially in the field of illegitimate security, with the rise of the transnational threat that has the limit of one country level response, transcending diplomatic and security cooperation between ASEAN countries and multilateral security councils including Korea. Further cooperation tends to be required. Since joining Korea's Treaty of Amity and Cooperation (TAC) in 2004, Korea has consistently promoted cooperation efforts in terrorism, drug and weapon trafficking, cybercrime, etc. Achieving "people-centred peace communities that live together well" between the competition and cooperation between the G2 countries' systems within the ASEAN is the focus of Korea's foreign ASEAN's foreign policy. The Kim Dae Jung government proposed a joint initiative led by South Korea on the economic crisis that blew up East Asia in 1997, and in the ASEAN + 3 Summit Meeting held in Brunei in 2001, "The East pursues peace, prosperity and development 'Asian Community' presented a vision".

South Korea overcame the East Asian currency crisis in the late 1990s, and secured their support by the foreign policy that forms mutual trust and friendly cooperation with ASEAN countries. Since then, Korea has focused on ASEAN's potential economics, has improved its national image for these countries, has formed a bilateral and multilateral diplomatic channel, and has secured its position as a credible partner. It is judged. However, the United States and China, who have actively implemented diplomatic practices focusing on the economic and geopolitical importance of Southeast Asia from the early days, and Japan lack a sustainable and progressive policy effort.

From 1999, Kim Dae Jung government up to now ASEAN policy has been limited to short-term issues, depending on the national administration issues of each government, without medium- and long-term goals and policy direction, vision. In addition, tensions in the Korean peninsula have sometimes lost continuity with the power that can develop into multilateral cooperation. South Korea, regardless of the conservative and progressive government, concentrated on diplomacy in the four outskirts (US, China, Japan, Russia), while the ASEAN countries are limited to the role and relationship as peripheral countries. However, he entered the Moon-Jane government, expanded the diplomatic horizon biased so far towards the four strengths, and promoted the "New South Policy" to strengthen relations with ASEAN and India, and exceeded the four strengths. Promotes “diversification of diplomacy”. However, while ASEAN's international 
status and geopolitical importance are increasingly expanded, multilateral cooperation between Korea and ASEAN is still weak. Therefore, through the "New South Policy", multilateral cooperation as well as close strategic cooperation on bilateral cooperation with each country, as well as an important agenda need to be established. As important agendas, various strategies can be considered, such as a strategy to deal with the four regions, such as the US-China competition, activation of multilateral cooperation within the region, and joint responses to transnational security issues.

ASEAN consists of emerging developing countries in Southeast Asia such as Vietnam, Myanmar and Indonesia, these countries will try to follow the experience of successful democratization and economic development through the "Han River Miracle" achieved by Korea. Recently, changes related to the fourth industrial revolution in the region have spread rapidly, and economic growth potential and potential have begun to draw attention. Since the late 1990s, Korea has played an important role in reducing development gaps between countries through the additional dynamic role of regional multilateral councils and Official Development Assistance (ODA), and It concentrates on efforts to anticipate roles and phases. As a whole, the terms of cooperation between South Korea's ASEAN and individual countries are friendly. However, there is always a fear that Korea will narrow its position due to competition between the US and China, which is gradually growing in the region, and efforts to expand diplomatic leadership in Japan. In addition, the region-specific "Asean system" limits the rapid and efficient joint response to transnational security issues. Therefore, based on economic interests, international relations, and regional characteristics, long-term cooperation consideration and constraint factors are taken into consideration. It is necessary to seek a viable security cooperation policy. The goal of Korea-ASEAN military cooperation proposed in this research is set as "building and expanding cooperation systems for strengthening economic security relations based on the improvement of ASEAN's international status". The establishment of a trust process corresponding to the change (identification of the exchange cooperation field), two joint efforts (the formation of a foreign security and security cooperation community) for the transnational issue within the region.

In Korea, ASEAN was incorporated (incorporated) as part of the Asia-Pacific region by 1994 and managed in the military cooperation priority region, but from the end of the 1990s, due to the consideration of considering the priority of the Northeast Asia region, It was managed by China's inferiority. However, relations with China, which had been a major economic partner, have been cooled down by Korea's third arrangement, etc., and South Korea will turn its attention to the ASEAN with the next best measures in mind. Since 2016, Korean distributors are accelerating their entry into Vietnam, Indonesia, etc. as substitutes for the Chinese market, entering the Moon Jane government and promoting the "New Southbound Policy" in the fourth industry, bio industry, smart In the fu- 
ture, we are aggressively starting to expand the market, including cooperation in the economic field, such as the construction of Citi.

At the beginning of 2019, the Singapore Southeast Asian Research Institute conducted a survey of strategic environment experts for 1000 foreign and security experts, bureaucrats and journalists in the ASEAN region, but more than half of the survey Mentioned the problem of the possibility of collisions in Experts in these areas have joined the Trump administration and $68 \%$ of those who rated US internal international relations and economic involvement have shrunk, more than $60 \%$ of whether the United States will help the region's strategic environment Made a negative decision. In addition, 45\% of respondents say that China will try to switch the strategic environment and order in the region, and about $68 \%$ of the respondents predicted the possibility because of the US-China conflict. As indicated in the questionnaire survey, ASEAN has not great G2 convictions and convictions, but is struggling with "strategic dilemmas" to keep in mind the possibility of clashes between these two countries. This can be managed by cooperative efforts in line with the G2 and the "strategic dilemma" of the peace and security on the Korean Peninsula. Denuclearization of North Korea through experiences of reform and opening up in Vietnam Cambodia, Laos Myanmar, etc. It can bring about reform and opening, and can expect an advisory role on investment for economic construction. From these macro perspectives, the Moon Jane government is promoting a new Southbound policy and is strengthening security cooperation and strategic cooperation. However, in order to build a true trusting relationship between Korea and ASEAN, it is possible if security cooperation such as foreign security, defense, and strategic sectors do not precede. However, for the Blueprint of ASEAN-Japan's security cooperation, the process of trusting relationship between multilateral cooperation prior to traditional security cooperation through the advance of unfair security cooperation such as environment, poverty, fog and infectious diseases. Construction is required.

The main features of today's international politics, including ASEAN, are related to complex issues across borders that are difficult for one country to solve. Disaster from joint problems such as terrorism and human rights issues. From disasters, poverty, water resource development and other regional specialization issues to issues requiring joint efforts, they are gradually increasing in various fields. The need for cooperation on transnational issues transcending a single country in ASEAN has been steadily raised since the 1950s, but urgency has not been clearly recognized. A transnational issue that occurs across borders is a disaster. It is classified as disasters, terrorism, poverty, infectious diseases, water resource development etc., but through the formation of "agreed rules of behavior and cooperative measures" among the states within the region triggered by "ASEAN Vision 2020" announced in 1997 Began to seek out solutions in earnest. Since the 1997 East Asian Monetary Crisis, ASEAN-Korea relations, including Korea, have been called for closer cooperation in various areas such as for- 
eign security, politics, economy, society and culture. Under these circumstances, ASEAN's transnational security issues were no longer confined to the region, but spread as issues that had a direct and indirect impact throughout East Asia. In fact, in ASEAN, up until now, the internal order of "respect for mutual sovereignty, internal policy non-intervention consultation and agreement" in the "Asean-style" framework has obstructed joint efforts among states. In the transnational security issue, although joint efforts and sacrifices beyond the interests of a single country should be prioritized, there has been no early fall and winter (improvement that policy discussions are impossible due to the limitations of the "Asean system") The Due to the repetition of these policy dissatisfactions, it is the fact that the efforts of regional cooperation are no longer progressing and only the enforcement of state-centered policies.

Lee Chang-Hyung (2012) is one of the threats of supranational security for peace and stability in the region. As a measure to expand joint efforts among ASEAN, share interests for peace and stability on the Korean Peninsula by participating and inviting various security dialogues in the region (ASEAN +3 , ARF, ADMM Plus, EAS, etc.), Presented the development of the "Human Security Threat Joint Response Initiative" that can contribute to the solution of Korea-led problems. The specific practice of security cooperation involves transnational security issues in East Asia and the Pacific region using the ASEAN Extended Defense Ministers Meeting (ADMM Plus), which is one of the methods of conversation presented earlier. You can expect a discussion about The ASEAN Extended Defense Council, which is held every other year, consists of the Defense Secretary's Council, the Defense Senior High-Level Council, the section manager's working group, and seven working groups at the practical level. Pirates are a recent issue. Distress. Meetings interested in multilateral cooperation to deal with supranational threats such as terrorist pollution are expanding. It must be developed into a major portion of regional security cooperation, doubling its pragmatic efforts, such as forming a standing council as the framework of the currently operating subcommittee.

\section{Conclusions}

So far, we have examined changes in East Asia's strategic environment, topological changes in ASEAN, strategic value in Korea, the need for military cooperation to increase cooperation among nations, and further promotion. Today, ASEAN's international influence has made significant movements in various areas such as economics, security and strategies in East Asia, such as the dynamic role of geopolitical, economic and multilateral cooperation. In the future, South Korea will reciprocate diplomacy in expanding the role of ASEAN, which is regarded as strategic practical "dynamic governance" in which the role and status of East Asia in the world are expanded and the strategic practical "dynamic governance" in it. We must strive for the development of the formation of relationships. ASEAN is located in Korea, it has a role as a supplement to relieve 
tension on the Korean peninsula in diplomacy and security, a role as a promoter for jumping to middle-sized countries in East Asia, and an economically rich resource, labor and defense industry. It is determined that the company offers new opportunities for export sales channels as its main target. However, 10 ASEAN countries have signed diplomatic ties with South Korea and North Korea as constraints, and North Korea is making full use of offensive strategies such as efforts to maintain military contact with former communist countries such as Cambodia and Laos. Therefore, it is necessary for South Korea to plan and actively approach multilateral cooperation plans with clear differentiation from North Korea's ASEAN entry strategy.

So far, Korea has concentrated on cooperation with the four major powers such as the United States, China, Japan, and Russia. However, as ASEAN's international status has moved to the center of East Asia, Korea needs to immediately improve its multilateral cooperation system with ASEAN. The way to cope with the current situation where these East Asian security landscapes are changing rapidly is to utilize the "army" where systems, resources and means are constantly built for each country, and it is argued that military support measures are most effective for the issue of transnational security for the military. In the situation where there are no regional experts within the Korean military, policy development is mainly focused on single projects that can achieve results in a short period of time, or relying solely on external expert policies, if you do not have expertise from the stage of policy formulation, you can stay in a form of exchange such as general relief business where military consideration factors are eliminated. Therefore, in order for military support to be provided efficiently, training of regional experts is urgently needed, and a two-track strategy consisting of physician crystals and business organizations is needed. The decision-making system needs access to the development of ADMM Plus, and complements the current situation of the districts that are repatriated without the department in charge of Southeast Asia and ASEAN (practice), at the dimension of the Ministry of Defense in order to strengthen the business organization. It is necessary to have a combination of professional activities (departments) composed of non-supporting balls (s).

Finally, in ASEAN, where East Asia's strategic importance and unlimited economic development potential are inherent, keep pace with the government's "New South Policy" and reciprocate relations between the military sector with these countries. Cooperation efforts to build are important. So far, Korea's military policy has been mostly concentrated in the United States, but recently it has been expanding cooperation with other major powers such as Japan, China, Russia and so on. It must be remembered that South Korea can only stay in the "marginal state" if it does not see and respond correctly to the Asian security situation. Through this research, we revisit the phase and reality seriously as strategic points of East Asia in ASEAN and demonstrate policy power to strengthen Korea's national interest and security in a changed security environment by 
breaking away from the four major powers and one-sided military policy.

\section{Conflicts of Interest}

The author declares no conflicts of interest regarding the publication of this paper.

\section{References}

[1] Lee, J.H. (2012) US-China Competition in South East Asia and Korea's Policy Direction. Korea National Research Institute, No. 2012-3171, 23, 93, 98.

[2] Juhogun (2014) Food Security as an Unorthodox Security Problem-Korean Implications. Oughtopia, 29, 127.

[3] Pyo, Y.J. (2010) Supernational Issues and Regional Governance in Southeast Asia. Korea Research Journal of Southeast Asia, 5, Preface 1. 